\title{
"LA MAQUINARIA AGRÍCOLA ARGENTINA. DESAFÍOS DE LA PRODUCCIÓN NACIONAL EN EL NUEVO DESARROLLISMO"
}

\author{
de José Vigil, Arturo Magri, \\ Melina Sacchi y Federico Langard. \\ Santa Fe, Editorial UNL, 2019. \\ por Lucas Salvador Caputto \\ Universidad Nacional del Litoral
}

La producción de maquinaria agrícola fue un segmento destacado de la política económica argentina entre 2001 y 2015, no por la dimensión o la escala de su producción sino porque fue presentada y colocada política, económica e incluso académicamente como una actividad industrial estratégica y simbólica de la matriz económica o modelo de acumulación de tipo nuevo desarrollista que se intentaba implementar, y que precisamente, intentaba un giro radical respecto del período inmediato anterior, al menos discursivamente. En lo referido a la maquinaria agrícola el modelo tuvo como característica central una fuerte intervención estatal, sobre todo nacional, con una estructura de incentivos macroeconómicos, sectoriales y regionales con un fuerte acento en la industria y en particular en la pequeña y mediana empresa. Dicho impulso hacia el sector tuvo su epicentro geográfico en la zona suroeste de Santa Fe, oeste de Córdoba, y norte de Buenos Aires.

Ahora bien, dicho eso, ¿en qué medida ese esquema de incentivos macroeconómico tuvo capacidad suficiente para direccionar a la industria de la producción de maquinaria agrícola y fomentar una mejora en su dinámica de producción, de innovación y sobre todo de 
en argentina, con muchas debilidades y falencias, pero virtuoso al fin. En esa alineación de elementos de múltiples geografías, la estrategia nacional de política macroeconómica y sectorial tuvo un rol fundamental: permitió unir las posibilidades sectoriales de la maquinaria agrícola con las oportunidades de los mercados internacionales favorables a la producción de maquinaria agrícola doméstica, y permitió acercar las inquietudes de los actores institucionales y empresariales del sector de la maquinaria agrícola con las necesidades políticas macroeconómicas del modelo de acumulación.

No es común encontrar libros de política industrial sectorial. Mucho menos sobre la industria de la Maquinaria Agrícola argentina. De allí que el libro tiene gran novedad en su temática misma. Pero a su vez tiene un gran esfuerzo de sistematización de datos sobe las problemáticas del sector, y de información sobre las políticas específicas sobre el sector, tanto impulsadas desde el ámbito nacional como desde las instancias regionales que han estado vinculadas a la promoción de la industria de producción de maquinaria agrícola. A su vez, aun con vuelo académico, el libro tiene un lenguaje práctico bastante cómodo para el lector, y un gran esfuerzo de presentación gráfica de la información recopilada.

El trabajo se estructura de la siguiente manera: primero se describe brevemente el proceso de transformación macroeconómica hacia el período denominado como nuevo desarrollista, que los autores sitúan con posterioridad al 2001, y se describe el intento de reindustrialización económica con una buena sistematización de las políticas económicas generales implementadas, pero también, y sobre todo, de la política sectorial de fomento a la producción de maquinaria agrícola. Allí se describe también de manera muy llevadera, gráfica y bien documentada, la manera en que el sector de la producción de maquinaria agrícola se convirtió en un sector políticamente estratégico y testimonial del intento reindustrializador.

En segundo lugar se trabaja sobre un tema clave del sector: la dinámica dual de su estructura empresarial; esto es, el diferencial comportamiento interno de los segmentos de actividad de producción de maquinaria agrícola, compuesto, por un lado, por la producción de tractores y cosechadoras, ampliamente dominados por empresas trasnacionales, y por otro, sembradoras e implementos agrícolas, segmento en el que Argentina tiene elementos para competir y que había mostrado un incipiente dinamismo exportador. El capítulo describe la manera en que durante los 90s en argentina se reestructuró el mercado de producción de maquinarias en argentina y se reconfiguró la dinámica de la cadena de valor, permitiendo a un puñado de empresas trasnacionales con alta desintegración vertical, fuertes economías de escala y gran habilidad para moverse globalmente, posicionarse mejor para competir con los esquemas de producción doméstica. El resultado de esa reestructuración —-según muestra el trabajo - no fue nada alentador para la producción nacional.

En tercer lugar, se trabaja sobre la idea de innovación en el sector y se plantea si el cuadro de incentivos macroeconómicos de fomento a la producción de maquinaria agrícola fue beneficioso para fomentar la innovación o si, por el contrario, los incentivos económicos actuaron adormeciendo la capacidad innovadora y la desidia del empresariado. Además, y aquí hay un punto interesante, el texto trabaja en una mirada crítica hacia el caudal de herramientas típicamente conocidas para el fomento de la innovación empresarial y que han estado basadas en las ideas de cercanía o proximidad física y enraizamiento local empresarial los que 
sumados a una adecuada infraestructura institucional son un potencial de competitividad y crecimiento, pero sobre todo de desarrollo (regional). A la luz de los resultados obtenidos en el estudio de caso, el capítulo abre la puerta a la necesidad de repensar el esquema de apoyo a la innovación empresarial del sector. Plantea entonces la necesidad de revisar las políticas de innovación y su relación con el espacio, en especial en la vinculación entre innovación y proximidad, avanzando hacia una consideración de políticas más abiertas y flexibles sobre la innovación.

En cuarto lugar, y como otra novedad de los estudios sectoriales y regionales, el texto analiza impactos sociales, y la manera en que el fomento a la actividad industrial sectorial pudo haber beneficiado a las localidades aledañas, sobre todo, desde que muchas de las políticas aplicadas, estaban basadas en esquemas conceptuales que traían consigo las promesas de "desarrollo". El trabajo propone un estudio exploratorio de correlación entre la conformación del espacio económico regional y las dinámicas sociales de la región conformada, intentando medir y analizar la evolución de aspectos claves como la dinámica poblacional, de empleo, de las condiciones habitacionales, de las condiciones de la estructura y la dinámica de algunas variables del sistema educativo, del sistema de salud, etc.

En definitiva, el trabajo de Vigil y sus colegas muestra que la producción de maquinaria agrícola en la etapa nuevo desarrollista, que tuvo un empuje significativo desde el cuadro de incentivos macroeconómico y desde las políticas sectoriales y regionales específicas, tuvo resultados ambiguos: pudo generar buenos resultados económicos y sociales, pero también tuvo muchas dificultades (e incapacidades) para revertir problemas estructurales en el sector. Como aporte adicional, el libro ofrece un diagnóstico actualizado de la situación del sector, aporta un panorama de lo que (eventualmente) se requiere para competir, y brinda a los hacedores de políticas un claro entendimiento de los caminos que deben tomarse para avanzar por la vía alta del desarrollo.

\section{PARA CITAR ESTE ARTÍCULO:}

Caputto, L.S. (2019). "Reseña bibliográfica: La maquinaria agrícola argentina. Desafíos de la producción nacional en el nuevo desarrollismo, de José Vigil, Arturo Magri, Melina Sacchi y Federico Langard", DAAPGE, año 19, № 33 (jul-dic), 2019, pp. 175-177. Santa Fe, Argentina: UNL. 